
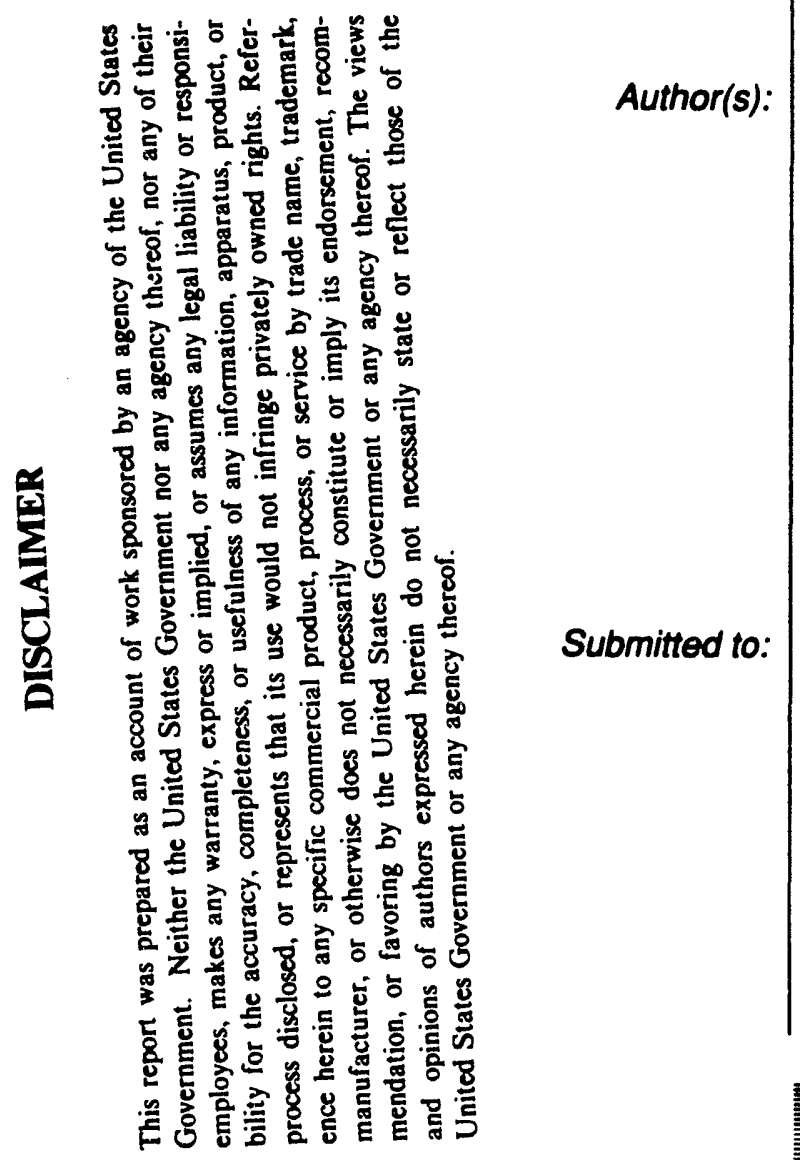

C. A. Beard, P. W. Lisowski, G. J. Russe11, and $L$. S. Waters

Global ' 93 - Future Nuclear Systems Energing Fuel Cycles and Waste Disposal Options September 12-17, 1993, Seattle, WA

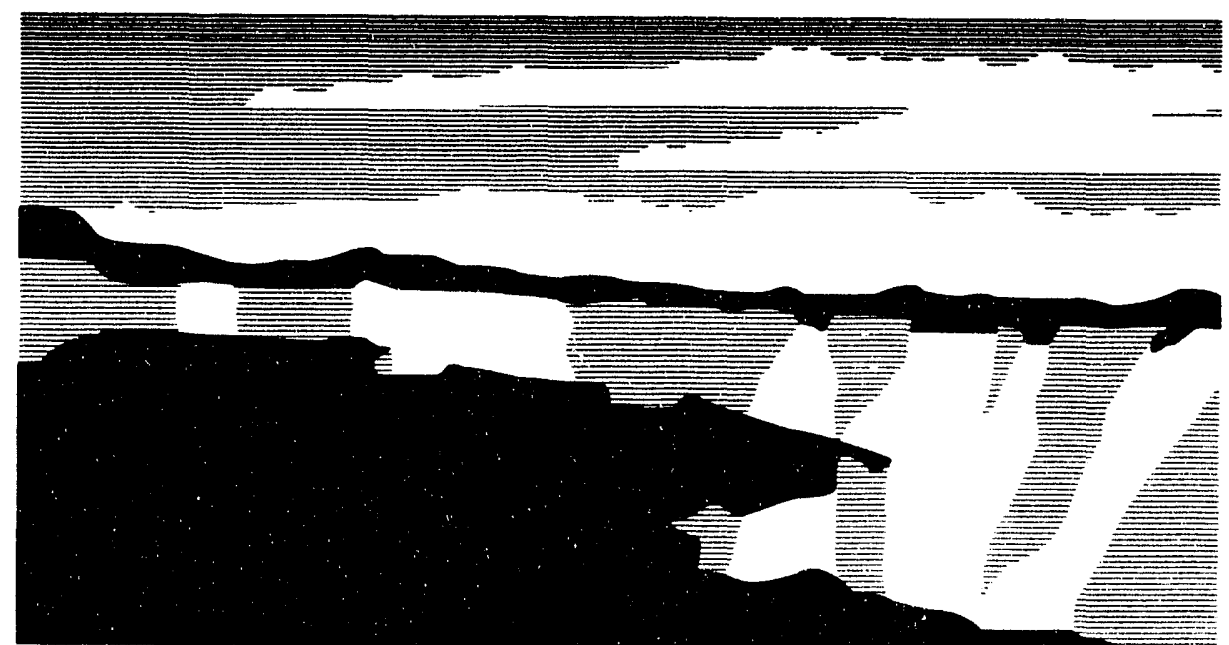

Los Alamos National Laboratory, an affirmative action/equal opportunity empldyer, is operated by the University of California for the U.S. Department of Energy under contract W.7405-ENG-36. By acceptance of this article, the publisher recognizes that the U.S. Government retains a nonexclusive, royalty-free license to publish or reproduce the published form of this contribution, or to allow others to do so. for U.S. Government purposes. The Los Alamos National Laboratory requests that the publisher identify this article as work performed under the auspices of the U.S. Department of Energy. 


\title{
COMPARISON OF ENERGY DEPOSITION CALCULATIONS BY THE LAHET CODE SYSTEM WITH EXPERIMENTAL RESULTS
}

\author{
C. A. Beard, P. W. Lisowski, G. J. Russell, and L. S. Waters \\ Los Alamos National Laboratory \\ Los Alamos, NM 87545
}

\section{ABSTRACT}

A comparison was performed between the energy deposition predicted by the LAHET Code System (LCS) ${ }^{1}$ with experimental values determined by Belyakov-Bodin et al. 2,3 for 800,1000 , and $1200 \mathrm{MeV}$ protons on targets composed of lead, bismuth, beryllium, carbon, and aluminum. The lead and bismuth showed agreement within approximately $10 \%$ at locations throughout the targets, and the agreement of the total energy deposited over the axial length of the targets ranged from $1 \%$ to $25 \%$. For the lead and bismuth cases, the LCS predictions were always greater than the experimental results. For the lighter materials, the agreement at locations throughout the target only agreed within approximately $20 \%$. No definable trend could be determined for the lighter materials since some LCS predictions were greater than the experimental results, some were less than the experimental results, and some showed very good agreement. The total energy deposited over the axial length of the targets was not compared for the lighter materials since it was not explicitly given with the experimental data.

\section{INTRODUCTION}

The LAHET Code System (LCS) ${ }^{1}$ is a useful tool for the analysis and design of systems incorporating accelerator-driven spallation neutron sources. The LCS allows for the continuous transport of particles beginning with high energies and following the initial particles as well as the resulting products throughout the entire energy range. Encompassed in this is the ability to determine the heat deposition in a system due to a variety of contributions, including coulombic heating from the slowing down of charged particles, neutron heating, and gamma heating. For many system designs, and especially for high-energy, highbeam-current applications, a major design factor is the amount of heat deposited in the system. Consequently, it is important that the accuracy for heat deposition predictions by the LCS is well known. Therefore, the goal of this study is to determine the precision of the LCS in making these predictions.

In order to estimate the accuracy of the LCS with regard to heat deposition, LCS predictions were compared with experimental results of Belyakov-Bodin, et al. 2,3. Comparisons were performed for protons with energies of 800,1000 , and 1200 $\mathrm{MeV}$ on lead, bismuth, beryllium, carbon, and aluminum. The lead and bismuth cases showed good agreement between the experimental results and the calculated values. However, for the lighter materials, the LCS was inconsistent in matching the experimental data.

\section{EXPERIMENTAL DETAIL $\mathbf{2 , 3}$}

The experimental apparatus consisted of 24 blocks, each $2.5 \mathrm{~cm}$ thick and $20 \mathrm{~cm}$ in diameter and fabricated with internal thermocouples for temperature measurements. Two techniques were used for fabricating the thermocouples into the target. The first, labeled the "whole measuring block" technique, involved inserting twelve measuring ends of differential thermocouples into a central disk and sealing them in such a way that the instantaneous temperature could be derived in two orthogonal directions at radii of $0.5 \mathrm{~cm}, 1.3 \mathrm{~cm}, 2.7 \mathrm{~cm}, 5.0 \mathrm{~cm}$, and $9.4 \mathrm{~cm}$. These temperatures were then converted to energy deposition through an analytical solution to the linear heat transfer equation. The second method, named the "cut measuring block" technique, divided the block into insulated rings with outer diameters of 2.0 $\mathrm{cm}, 5.0 \mathrm{~cm}, 10 \mathrm{~cm}$, and $20 \mathrm{~cm}$. Three ends of differential thermocouples were inserted into each ring. The energy deposition was then measured directly as the integrated temperature variation of a chosen thermally insulated ring. For the lead and bismuth results, each data point is labeled with the technique by which it was obtained. For the beryllium, carbon, and aluminum results, Belyakov-Bodin et al. state that the same techniques were used, but do not label the data.

\section{THE LCS MODEL}

The LAHET/MCNP geometry which modeled the experimental configuration consists of a cylinder divided into a total of 48 cells, each $2.5-\mathrm{cm}$ thick divided into two radial regions $(\mathrm{r}<5 \mathrm{~cm}$ and $5 \mathrm{~cm}<r<10 \mathrm{~cm}$ ) as shown in Fig. 1. The total energy deposition in each cell was calculated by adding the LAHET energy deposition determined by an HTAPE analysis of the history tape (type 6 edit with the contributions from nuclear excitation and $\pi^{0}$ decay subtracted) with the coupled neutronphoton energy deposition from MCNP (type 6 tally). In order to match the quantities determined in the experiment, the total energy deposited to a radius of both $5 \mathrm{~cm}$ and $10 \mathrm{~cm}$ for each axial cell was determined. These values were then divided by $2.5 \mathrm{~cm}$ to yield the units of energy per unit length. The axial locations for these values were assumed to be the axial mid-point of each cell.

The proton beam distribution in the experiment was stated to approximate a Gaussian distribution with FWHM=2.4 $\mathrm{cm}^{2,3}$. Therefore, for the LAHET calculations, a Gaussian distribution with a $\sigma=1.0213 \mathrm{~cm}$ was used. The authors also state that the beam had an inclination of $2^{\circ} \pm 1^{\circ}$ and a beam divergence of $0.5^{\circ} \pm 0.2^{\circ}$ for the lead and bismuth experiments. These effects were not accounted for in the LAHET calculations. 

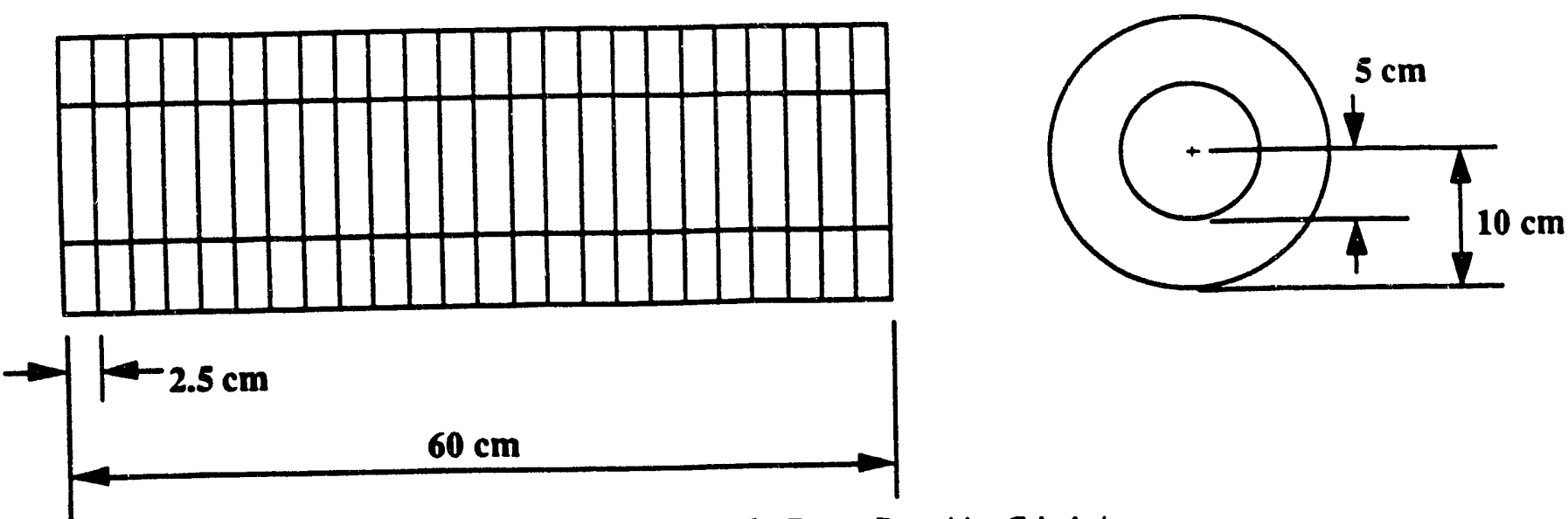

Figure 1: LCS Geometry for Enirgy Deposition Calculations

The BERTINI nuclear cascade model was used for all of the LAHET calculations, except for two test cases which were performed with the ISABEL nuclear cascade model to determine if better agreement could be obtained with the experiments involving the lighter materials. The ISABEL results are labeled as such, and all cther predictions should to assumed to be from the BERTINI model.

The default input parameters were used for the LAHET calculations with the exception of the implementation of the preequilibrium model following the intranuclear cascade, the inclusion of elastic scattering, and allowing for the transport of heavy charged particles (which for the BERTINI model only includes slowing down).

Belyakov-Bodin et al. did not give the densities of the materials used in the experiments. Therefore, the densities were assumed to be the natural densities of the pure materials. The $v$ alues used in the LCS model are shown in Table I.

Table I: Assumed Densities for LCS Calculations given.

\begin{tabular}{|l|l|}
\hline Material & Density $\left(\mathrm{g} / \mathrm{cm}^{3}\right)$ \\
\hline Beryllium & 1.85 \\
Carton & 1.60 \\
Aluminum & 2.70 \\
Lead & 11.3 \\
Bismuth & 9.8 \\
\hline
\end{tabular}

\section{RESULTS}

Table II gives the total energy deposited over the entire length of the targets out to the two radii $(5 \mathrm{~cm}$ and $10 \mathrm{~cm})$ tested for the lead and bismuth targets. The total energy deposition in the beryllium, carbon, and aluminum targets was not given. As can be seen from Table II, the LCS predicts total energy deposition values $14-25 \%$ in excess of those determined experimentally for the lead target cases, and $1-25 \%$ in excess for the bismuth target cases. In all of the lead and bismuth cases, predictions out to a $10 \mathrm{~cm}$ radius are in better agreement than those for $5 \mathrm{~cm}$, indicating a possible discrepancy between the stated and actual beam distribution. Figures 2 and 3 are plots of the experimental data and LCS predictions for $1000 \mathrm{MeV}$ protons on lead. Figures 2 and 3 show that the LCS values have the largest disagreement with the experimental data at small depths into the target, with the agreement improving as the depth increases. This pattern was observed in all the lead and bismuth cases.
For the beryllium targets, the LCS overpredicts the energy deposition throughout the length of the targets for all proton energies. Figures 4 and 5 show the results for $1000 \mathrm{MeV}$ protons, which is characteristic for the beryllium cases. The agreement between the LCS predictions and the experimental data for the beryllium targets is the worst for all of the materials tested. The LAHET/MCNP model was checked extensively, and is consistent with the information given by Belyakov-Bodin et al., and with the models for the other materials. Alterations were made in an attempt to detect any discrepancies in the description of the experiments (such as replacing beryllium with beryllium oxide). but no significent improvement was obtained.

The results for $i=$ carbon targets display different behavior for different proton energies. For $800 \mathrm{MeV}$ protons, the LCS underpredicts the energy deposition within a $5 \mathrm{~cm}$ radius, but accurately depicts the energy deposition out to a radius of $10 \mathrm{~cm}$. However, for $1000 \mathrm{MeV}$ protons, LCS predictions agree with the experimental values within $5 \mathrm{~cm}$, but predictions out to $10 \mathrm{~cm}$ are greater than those determined by Belyakov-Bodin et al. Similarly, for $1200 \mathrm{MeV}$ protons, LCS calculations show good agreement out to $5 \mathrm{~cm}$, but overpredict the energy deposition with a radius of $10 \mathrm{~cm}$ throughout the length of the target.

Aluminum is the only target material for which the LCS predicts values which are consistently lower than those determined experimentally. This is shown in Figs. 6 and 7 which give the 800 $\mathrm{MeV}$ proton results. As the proton energy is increased, though, the agreement between LCS predictions and experimental values improves for both radii tested. For $1200 \mathrm{MeV}$ protons, the LCS values match the experimental results very well as can be seen in Figs. 8 and 9.

\section{CONCLUSIONS}

The fact that the LCS predictions agree very well with experimental values in some cases, show obvious deviations in others, yet display no pattern with regard to direction or magnitude of the discrepancy, and no obvious trend related either to atomic mass of the target or energy of the proton beam, makes it impossible to form any firm conclusion as to the performance of the LCS model in predicting heat deposition. Several possible reasons exist (among others) for these results including the following:

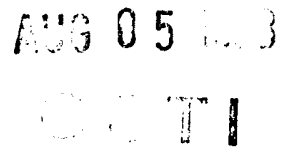


Table II: Total Energy Deposited Over Axial Length for $R=5 \mathrm{~cm}$ and $R=10 \mathrm{~cm}$

\begin{tabular}{|c|c|c|c|c|c|c|}
\hline Material & $\begin{array}{l}\text { Proton } \\
\text { Energy } \\
\text { (MeV) }\end{array}$ & $\begin{array}{l}\text { Radius } \\
\text { (cm) }\end{array}$ & $\begin{array}{l}\text { Belyakov- } \\
\text { Bodin } \\
\text { et al. }\end{array}$ & $\begin{array}{l}\text { Quoted Exp. } \\
\text { Error } \\
(\%)\end{array}$ & LCS & $\begin{array}{l}\text { Error } \\
\text { Between } \\
\text { Calc. and } \\
\text { Exp. }(\%)^{*}\end{array}$ \\
\hline $\begin{array}{l}\mathrm{Pb} \\
\mathrm{Pb} \\
\mathrm{Pb} \\
\mathrm{Pb} \\
\mathrm{Pb} \\
\mathrm{Pb} \\
\mathrm{Bi} \\
\mathrm{Bi} \\
\mathrm{Bi} \\
\mathrm{Bi} \\
\mathrm{Bi} \\
\mathrm{Bi}\end{array}$ & $\begin{array}{l}800 \\
800 \\
1000 \\
1000 \\
1200 \\
1200 \\
800 \\
800 \\
1000 \\
1000 \\
1200 \\
1200\end{array}$ & $\begin{array}{l}5 \\
10 \\
5 \\
10 \\
5 \\
10 \\
5 \\
10 \\
5 \\
10 \\
5 \\
10\end{array}$ & $\begin{array}{l}380 \mathrm{MeV} \\
460 \mathrm{MeV} \\
450 \mathrm{MeV} \\
520 \mathrm{MeV} \\
530 \mathrm{MeV} \\
600 \mathrm{MeV} \\
430 \mathrm{MeV} \\
520 \mathrm{MeV} \\
470 \mathrm{MeV} \\
570 \mathrm{MeV} \\
470 \mathrm{MeV} \\
570 \mathrm{MeV}\end{array}$ & $\begin{array}{l}7 \\
10 \\
7 \\
10 \\
8 \\
11 \\
4 \\
6 \\
4 \\
6 \\
8 \\
10\end{array}$ & $\begin{array}{l}475 \mathrm{MeV} \\
523 \mathrm{MeV} \\
540 \mathrm{MeV} \\
608 \mathrm{MeV} \\
611 \mathrm{MeV} \\
687 \mathrm{MeV} \\
469 \mathrm{MeV} \\
525 \mathrm{MeV} \\
526 \mathrm{MeV} \\
600 \mathrm{MeV} \\
589 \mathrm{MeV} \\
672 \mathrm{MeV}\end{array}$ & $\begin{array}{l}25 \\
13.7 \\
20 \\
16.9 \\
15.28 \\
14.5 \\
9.07 \\
0.96 \\
11.9 \\
5.26 \\
25.3 \\
17.9\end{array}$ \\
\hline
\end{tabular}

Error defined as (Calc. Value - Exp. Value)/(Exp. Value)

1) The energy deposition predictions by LAHET/MCNP are highly dependent on the density of the material. For these calculations, the densities that were assumed are shown in Table I. If the actual target materials differed from these values, the predictions would be inaccurate. However, the only material this is likely for is beryllium for which the LCS consistently overpredicted the energy deposition values. In all of the other materials, some of the caiculations matched the experimental values well; thus a change in density would most likely cause these calculations to become inaccurate.

2) The Intranuclear Cascade/Evaporation model could incorrectly model interactions with low- $Z$ materials. This could cause each material to follow its own individual trend, while displaying no apparent pattern in results when changing from one material to another. This would also explain the good results obtained for the lead and bismuth cases. In an attempt to determine whether the high-energy transport model might be a factor in the erratic results, the ISABEL ${ }^{1}$ intranuclear cascade/evaporation model was used instead of the BERTINI model and $1000 \mathrm{MeV}$ protons on beryllium (for which the BERTINI model overpredicted the heat deposition) and $800 \mathrm{MeV}$ protons on aluminum (for which the BERTINI model underpredicted the heat deposition) were analyzed. The beryllium results are shown in Figs. 10 and 11, and the aluminum results are shown in Figs. 12 and 13. Comparison of the beryllium results with the BERTINI predictions (see Figs. 4 and 5) shows that the ISABEL model does more closely match the experimental predictions, although still overpredicting the heat deposition out to a radius of $10 \mathrm{~cm}$. However, the aluminum predictions by ISABEL (Figs. 12 and 13) are slightly worse than the BERTINI results (Figs. 6 and 7). Also, the ISABEL results follows similar trends as the BERTINI predictions. Consequently, while the choice of model does make some difference, it does not eliminate the discrepancies. It should be noted that since both models were developed using the same theuretical basis, it is entirely possible that both models have problems predicting interactions for particles on low- $Z$ materials.

Although discrepancies were observed, all of the calculated data points agreed with the experimental results within approximately $20 \%$. Consequently, although the results for the lead and bismuth cases indicate that the LCS accuracy might be even better, heat deposition predictions can be considered (especially for heavy materials) to be within $20 \%$ of the actual values.

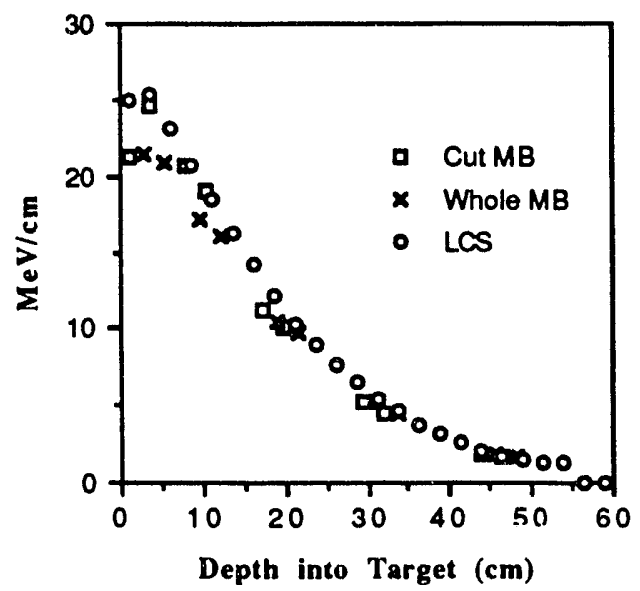

Figure 2: Energy Deposition for $1000 \mathrm{MeV}$ Protons on Lead for a Radius of $5 \mathrm{~cm}$

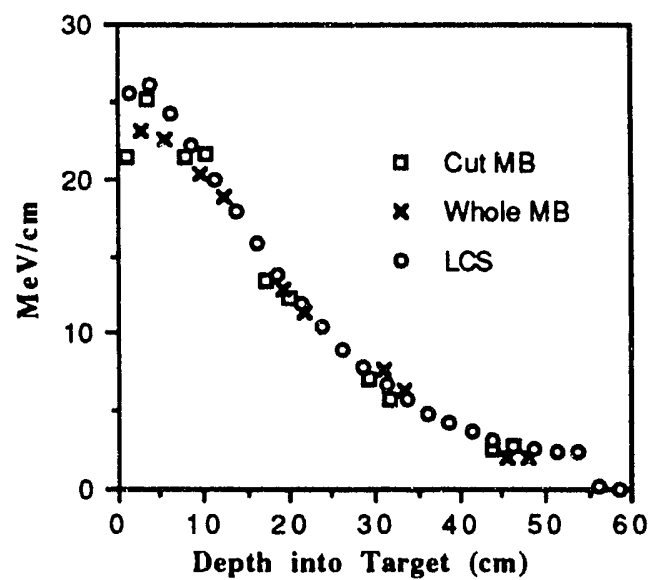

Figure 3: Energy Deposition for $1000 \mathrm{MeV}$ Protons on Lead for a Radius of $10 \mathrm{~cm}$ 


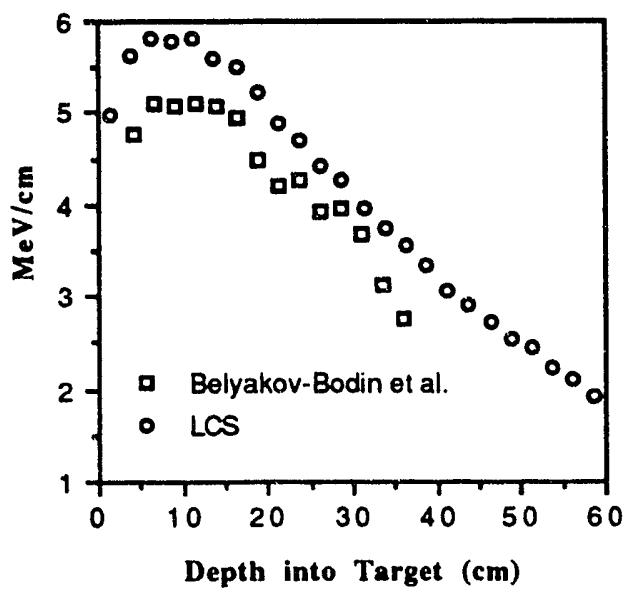

Figure 4: Energy Deposition for $1000 \mathrm{MeV}$ Protons on Beryllium for a Radius of $5 \mathrm{~cm}$

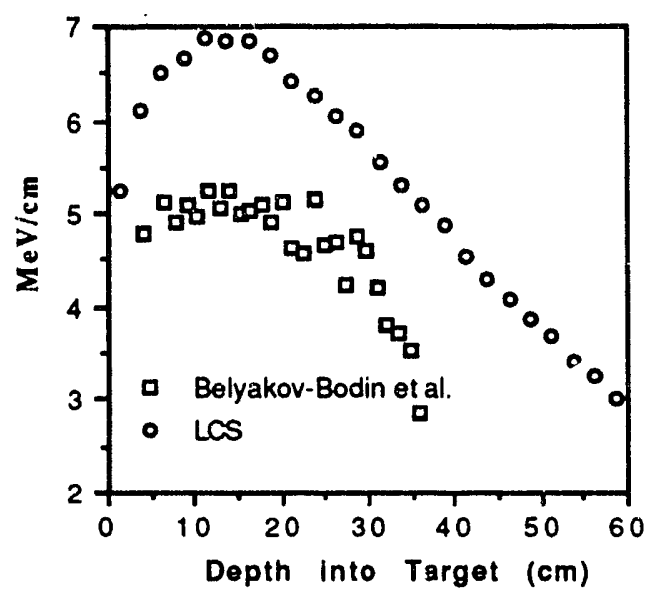

Figure 5: Energy Deposition for $1000 \mathrm{MeV}$ Protons on Beryllium for a Radius of $10 \mathrm{~cm}$

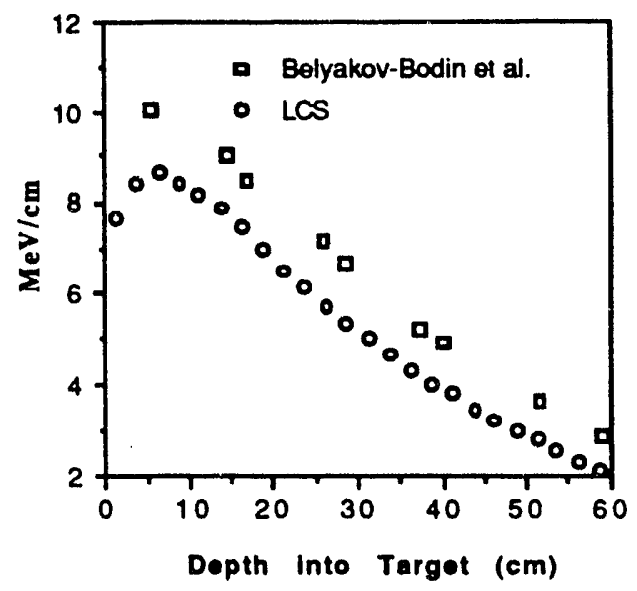

Figure 6: Energy Deposition for $800 \mathrm{MeV}$ Protons on Aluminum for a Radius of $5 \mathrm{~cm}$

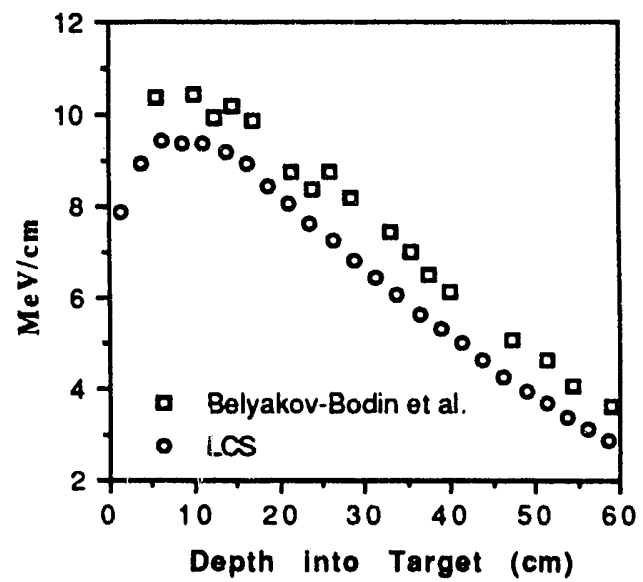

Figure 7: Energy Deposition for $800 \mathrm{MeV}$ Protons on Aluminum for a Radius of $10 \mathrm{~cm}$ 


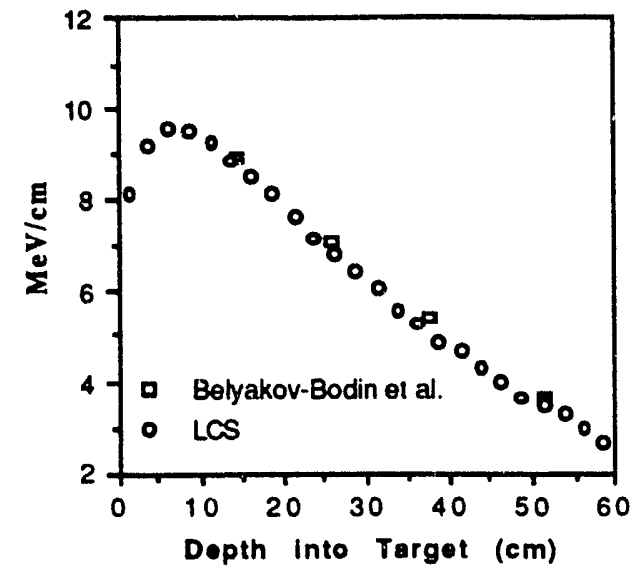

Figure 8: Energy Deposition for $1200 \mathrm{MeV}$ Protons on Aluminum for a Radius of $5 \mathrm{~cm}$

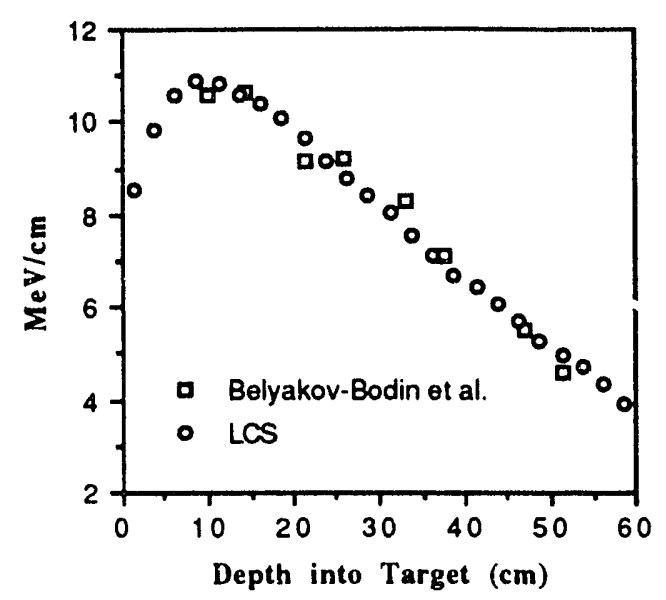

Figure 9: Energy Deposition for $1200 \mathrm{MeV}$ Protons on Aluminum for a Radius of $10 \mathrm{~cm}$

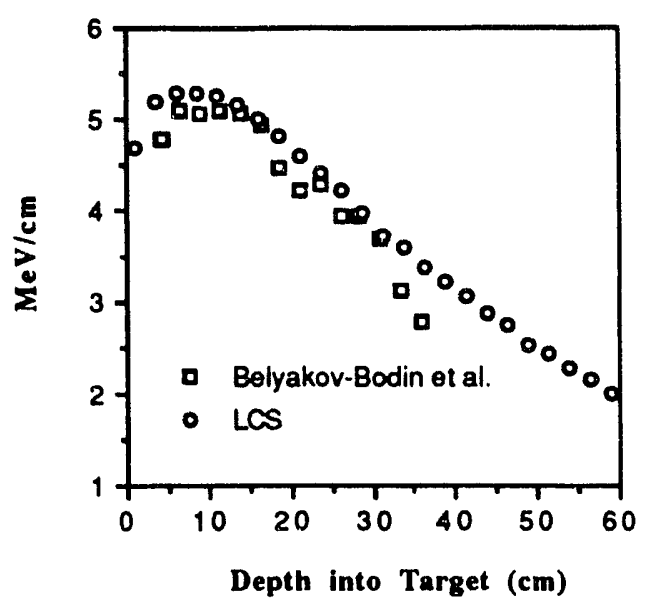

Figure 10: Energy Deposition for $1000 \mathrm{MeV}$ Protons on Beryllium for a Radius of $5 \mathrm{~cm}$ Determined Using the ISABEL

Intranuclear Cascade/Evaporation Model

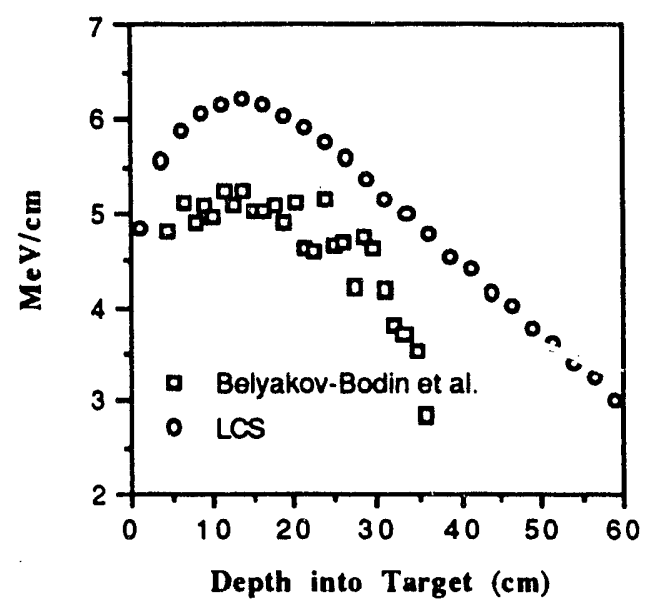

Figure 11: Energy Deposition for $1000 \mathrm{MeV}$ Protons on Beryllium for a Radius of $10 \mathrm{~cm}$ Determined Using the ISABEL Intranuclear Cascade/Evaporation Model 


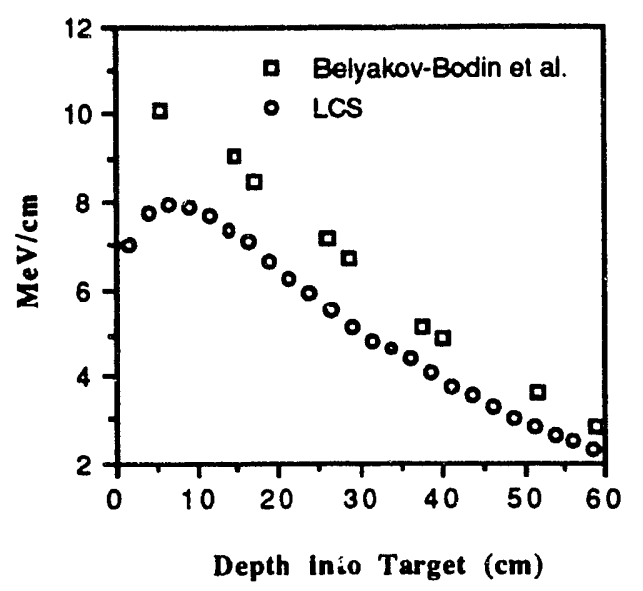

Figure 12: Energy Deposition for $800 \mathrm{MeV}$ Protons on Aluminum for a Radius of $5 \mathrm{~cm}$ Determined Using the ISABEL Intranuclear Cascade/Evaporation Model

\section{REFERENCES}

1. k. E. PRAEL and H. LICHTENSTEIN, "User Guide to LCS: The LAHET Code System," LA-UR-89-3014, Los Alamos National Laboratory (1989).

2. V. I. BELYAKOV-BODIN, et al., "Calorimetric Measurements and Monte Carlo Analyses of Medium-Energy Protons Bombarding Lead and Bismuth Targets," Nuclear Instruments and Methods in Physirs Research, A295, 140-146 (1990).

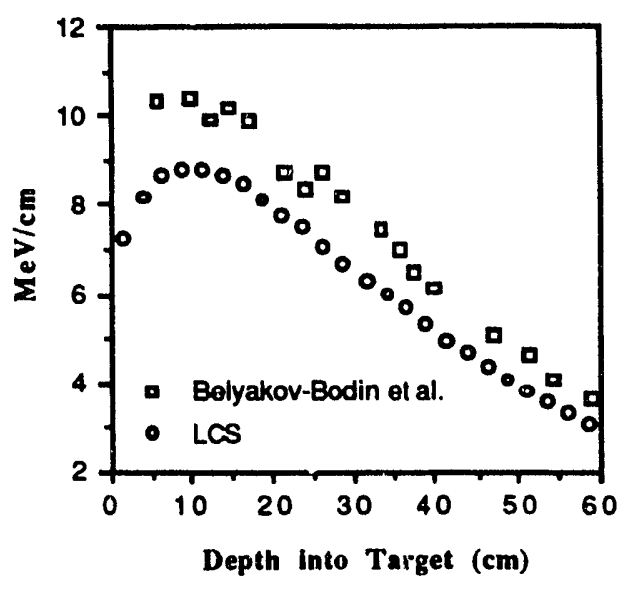

Figure 13: Energy Deposition for $800 \mathrm{MeV}$ Protons on Aluminum for a Radius of $10 \mathrm{~cm}$ Determined Using the ISABEL

Intranuclear Cascade/Evaporation Model

3. V. I. BELYAKOV-BODIN, et al., "Calorimetric Measurements of Medium-Energy Protons Bombarding Beryllium, Carbon, and Aluminum Targets," Nuclear Instruments and Methods in Physics Research, A314, 508-513 (1992). 

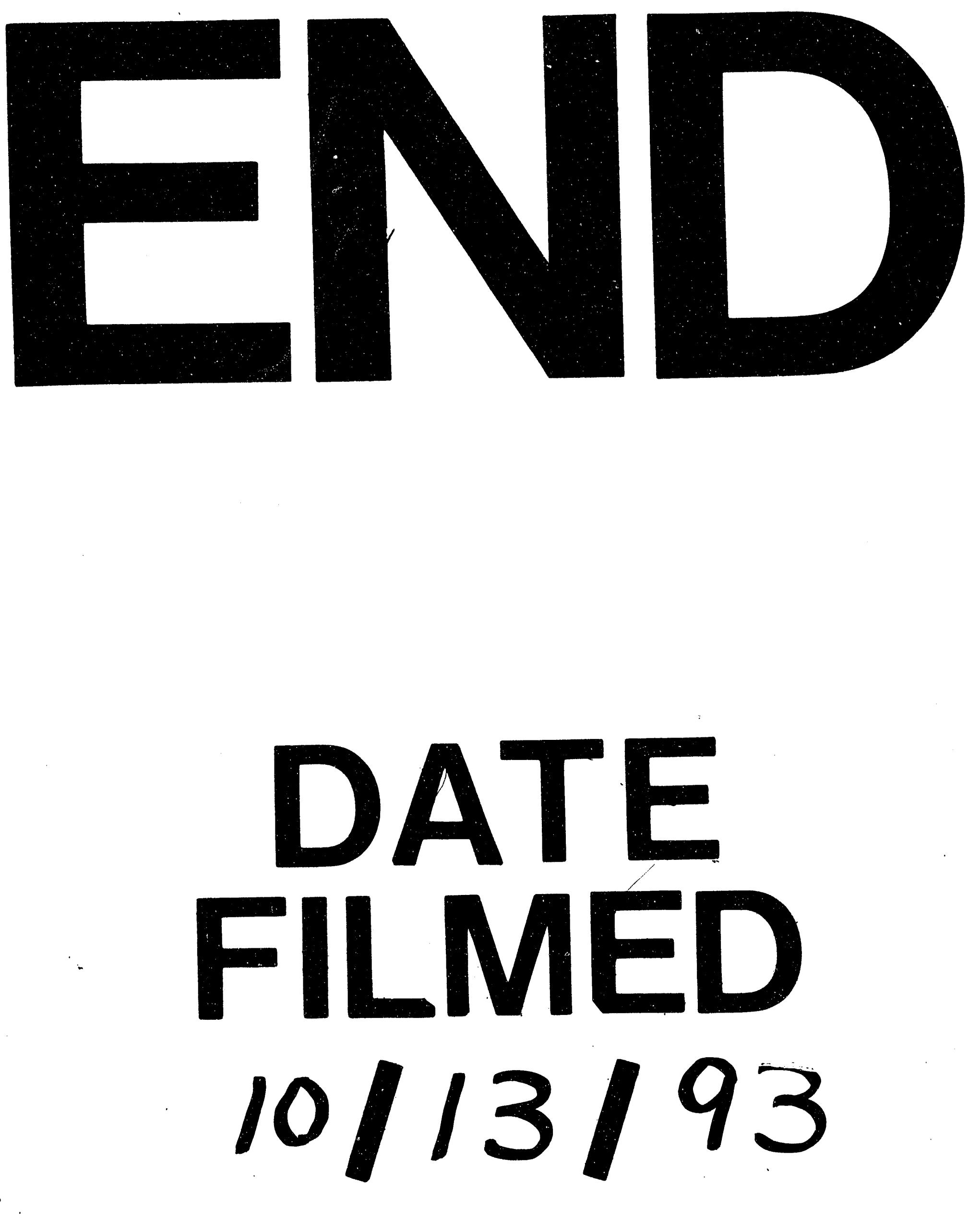
